\title{
Developing the Indicators for Monitoring the Adaptation Actions for Quang Ngai Province, Viet Nam using the Delphi Technique
}

\section{Chu Thi Thanh Huong1 1 , Huynh Thi Lan Huong², Tran Thuc²}

\author{
${ }^{1}$ Department of Meteorology, Hydrology and Climate Change, Ministry of Natural Resources and Environment, \\ Viet Nam \\ ${ }^{2}$ Vietnam Institute of Meteorology, Hydrology and Climate Change, Ministry of Natural Resources and \\ Environment, Viet Nam
}

\begin{abstract}
The Paris Agreement requests to establish the transparency framework to clarify, and track the progress towards achieving Parties' National Determined Contributions and Parties' adaptation actions. Monitoring Reporting and Verification (MRV) for adaptation aims to enhance the transparency, and to check progress and the effectiveness of the adaptation actions. Developing the indicators for monitoring the adaptation actions contributes to the development of the adaptation MRV system. This paper focuses on the process of establishing the indicators to monitor adaptation action in forestry sector, Quang Ngai Province, Viet Nam. After two rounds of the Delphi technique are applied, the indicators are then grouped into 3 clusters based on the Result Based Management tool (Adaptation Capacity, Adaptation Actions, and Sustained Development in climate change) to identify the effectiveness of adaptation action. Our study found that 8 out of 10 indicators were ranked in the 4-5 range (likely relevant to highly relevant), which means they should be applied in Quang Ngai province. As indicated by the experts, 02 indicators (Salinity, and Percentage of saltwater intrusion areas) were not appropriate due to the unclear effectiveness of adaptation action. The set of indicators could be used to monitor the progress of project implementation. Monitoring the implementation progress of adaptation action contributes to the commitment of adaptation component under Vietnam's NDC and the development of the MRV system for adaptation. The MRV for adaptation needs to be further researched and developed.
\end{abstract}

Keywords: Indicator, Monitoring, Adaptation, Delphi Technique

\section{Introduction}

Quang Ngai is in South-Central Vietnam, a poor province with frequent flash floods, landslides in the mountainous area; inundation, salt intrusion, river bank and coastline erosion in the plain and coastal area; and extreme weather conditions in the surrounding islands.

In response to climate change, the action plan has been developed in Quang Ngai province for the period 2011-2015 focusing on 4 main components: (i) issuing climate change documents; (ii) developing solutions to respond to climate change and sea level rise (during the periods of 2011-2020 and post 2020); (iii) conducting pilot activities to respond to climate change; (iv) and raising public awareness (Quang Ngai's PC, 2015). However, due to financial and human resources shortages, the action plan was not been fully implemented. Fours climate change related projects were approved for implementation during this period, but the monitoring indicators for adaptation actions were not developed. This study contributes to developing the MRV system at the project level, enhancing the transparency of actions under the Paris Agreement.

\begin{abstract}
Methods
Considering the purpose of the research, and its suitability for the development of the monitoring indicators, the Delphi Technique, the consultation process to get the consensus of the experts on a particular issues, was selected as the main methodology of this research and used from January to June 2016. The Delphi Technique has been used since 20th century with 2 distinct forms of process: Conventional Delphi and Delphi Conference. They are both carried out in 4 phases: (i) explore the subject under discussion, (ii) reach and understand the group's
\end{abstract}

This article is published under the terms of the Creative Commons Attribution License 4.0

Author(s) retain the copyright of this article. Publication rights with Alkhaer Publications.

Published at: http://www.ijsciences.com/pub/issue/2017-06/

DOI: 10.18483/ijSci.1341; Online ISSN: 2305-3925; Print ISSN: 2410-4477 
views on the issue, (iii) identify the underlying problems in case of significant disagreements, (iv) and conduct final evaluation (Harold A. Linstone, 2002).

Delphi is applied in many different fields: Economics, Environment, Sustainable Development, Land Economy, Agriculture, Transportation, Nursing Education, Tourisms... and Climate Change. For climate change adaptation, Assoc. Prof. Nguyen An Thinh used Delphi questionnaires to figure out how local communities adapt to climate changes along heavily damaged coasts. The result shows that the development of sustainable ecosystems, upgraded New Rural Planning, and renewable energy strategies could be adaptation options to cope with climate change in Ha Tinh province, Viet Nam (Nguyen An Thinh, 2017). For this study, the Delphi Conference form is applied to select the indicators to track the progress of implementation of adaptation actions in forestry sector.

\section{The process of selecting the indicator using the Delphi technique}

The 08 steps of the Delphi process for preconsultation, consultation and post-consultation phases from January to September 2016 are as follow:

\section{- Pre-Consultation phase}

Step 1. Select the experts to be involved in the Delphi process (January 2016)

The number of experts varies from study to study, from as many as 3-5 people (Le Trinh Hai, 2015); 7 people (Chu and Hwang, 2007; Le Trinh Hai, 2009); 36 members (An Thinh Nguyen, 2017).. Selecting the proper expert panel is important because their opinions decide the suitable indicators for the study's purpose. Depending on the adaptation project type, the specific characteristics of Quang Ngai province, and the specifications of the expert panel, 9 experts were selected: 2 from universities; 3 from research institutes; 2 from Department of Hydrology, Meteorology and Climate Change, and 2 from Department of Natural resources and Environment in Quang Ngai Province. The experts' background are also widely different: Water resources and Hydrology, Water and Environment Engineering, Environmental Management, Urban Engineering and Climate Change.

Step 2. Set up the monitoring criteria based on the Result Based Management (RBM) tool that is a logical framework as core methods of its M\&E system (February 2016)

RBM captures the quality of implementation. The M\&E system helps to track the implementation result for short term ( $<5$ years), medium term (5-20 years), and long term (> 20 years). M\&E often emphasises more on the quantitative indicators. It is more challenging to develop the qualitative indicators. To identify the contribution to adaptation, a three part framework is proposed: adaptive capacity (AC), adaptation actions (AA), and sustained development (SD) (GIZ, 2011). The monitoring criteria is arranged in 3 groups (AC, AA, and SD) for consultation using the Delphi technique to check the implementation result of the short term period. The RBM was applied and the indicators were arranged in the 3 part framework.

Step 3. Set up the questionnaire based on the results of adaptation actions. In this step, all questionnaires were open for discussion (February 2016)

The indicator was set up for each of the project result.

\section{- Consultation phase}

Step 4. Conduct First Round of the Delphi process (March 2016)

Using open-ended questionnaires, a meeting with the 9 experts were conducted in Quang Ngai province. The 9 experts were requested to rate their degree of agreement to the indicator. The level of agreement is ranked from 1 to 5 as follow: (1) means highly irrelevant; (2) means likely irrelevant; (3) means more or less relevant; (4) means likely relevant; (5) means highly relevant.

Step 5. Analyse of data for first round (March 2016)

Based on the rating results, a Rating Median (Md), Quartile deviation (Q), Rating Mean and Rating Variance (\%) were calculated as shown in the Table 2. The analysis was based on the rules of the Delphi Technique as used in a KAMET set up (Table 2).

Step 6. Conduct Second Round of the Delphi process (April 2016)

The questionnaires were sent to the 9 experts again to seek their consensus or stability of the panel member's responses. Rating Median (Md), Quartile deviation (Q), Rating Mean and Rating Variance (\%) were recalculated as shown in the Table 2. According to Chu, Hwuang 2007, Le Hai Trinh 2009, the indicator was not used if an expert failed to respond to certain criteria statements.

\section{- Post-consultation phase}

Step 7. Analyse of data for second round (May 2016)

After the data of Round 2 were collected, the results were analysed. The analysis was based on the rules of the Delphi Technique as used in a KAMET set up (Table 1). Rating Median (Md), Quartile deviation 
(Q), Rating Mean and Rating Variance (\%) were recalculated as shown in the Table 2 .

In case all the questionnaire items are either accepted or rejected, or the rating mean is higher than 3.5 and their rating variant values are being less than $15 \%$, the Delphi process is finished (Chu and Hwang, 2007). In this study, strong agreement was reached and met the rules of Delphi Technique used in a KAMET set up.
Therefore the 3rd round was not necessary. The set of indicators for the adaptation action was prepared for the further research.

Step 8. Reporting the result to the expert panel (June 2016)

The summarized report with the conclusion was sent to the expert panel for record and reference.

Table 1. Rules for analysing the ratings from multiple experts with Delphi approach (Chu and Hwang, 2007)

\begin{tabular}{lll}
\hline Round $\boldsymbol{t}$ & Round $\boldsymbol{t}+\boldsymbol{1}$ & Round $\boldsymbol{t}+\mathbf{2}$ \\
\hline Rating mean $\left(\mathrm{q}_{\mathrm{i}}\right) \geq 3.5$ & $\begin{array}{l}\text { If rating mean }\left(\mathrm{q}_{\mathrm{i}}\right) \geq 3.5, \mathrm{Q} \leq 0.5 \text { and } \\
\text { rating variance }\left(\mathrm{q}_{\mathrm{i}}\right)<15 \% \text {, then } \mathrm{q}_{\mathrm{i}} \text { is } \\
\text { accepted, and no further discussion } \\
\text { concerning } \mathrm{q}_{\mathrm{i}} \text { is needed. }\end{array}$ \\
\hline Rating mean $\left(\mathrm{q}_{\mathrm{i}}\right)<3.5$ & $\begin{array}{l}\text { If Rating mean }\left(\mathrm{q}_{\mathrm{i}}\right)<3.5 \text { and } \mathrm{Q} \leq 0.5 \quad \text { If rating mean }\left(\mathrm{q}_{\mathrm{i}}\right) \geq 3.5, \mathrm{Q} \leq 0.5 \text { and } \\
\text { and rating variance }\left(\mathrm{q}_{\mathrm{i}}\right) \leq 15 \% \text { then } \mathrm{q}_{\mathrm{i}} \quad \begin{array}{l}\text { rating variance }\left(\mathrm{q}_{\mathrm{i}}\right) \leq 15 \% \text { then } \mathrm{q}_{\mathrm{i}} \text { is } \\
\text { accepted, and no further discussion }\end{array} \\
\text { is rejected, and no further discussion } \\
\text { concerning } \mathrm{q}_{\mathrm{i}} \text {, is needed. }\end{array}$ \\
\hline
\end{tabular}

Note: Rating mean $\left(\mathrm{q}_{\mathrm{i}}\right)$ : the mean of the ratings for questionnaire item $\mathrm{q}_{\mathrm{i}}$ and Rating variance $\left(\mathrm{q}_{\mathrm{i}}\right)$ : the ratio of experts who change their ratings for qi and $\mathrm{Q}$ is the quartile.

\section{Result and Discussion}

The study applied 8 steps of the Delphi process for the "Reforestation and restoration of coastal mangroves in Binh Thuan Commune, Binh Son district, Quang Ngai province" project

The objective of the project is to prevent soil erosion, to enhance the protective capacity, to regulate the climate, to protect the coastal ecosystem, to prevent saltwater intrusion, to protect groundwater in the area, and to create the livelihood for local people. The main activity of project is to plant 100 ha forest, restoring 30 ha of the coastal protective forest in Binh Thuan Commune in order to contribute to the safety of life and property for about 850 households, 3,200 people especially in the rainy season (Quang Ngai's PPC, 2013).

The indicators are based on the result of the project's activity and grouped in 3 clusters, namely Adaptation Capacity (AC), Adaptation Actions (AA) and Sustained Development in the changing climate (SD). For this project, $05 \mathrm{AC}$ indicators have been developed including: AC1 - Percentage of mangrove forests of the total natural land area (\%); AC2 Salinity $(\mathrm{g} / \mathrm{l})$; AC3 -Percentage of saltwater intrusion area (\%); AC4 - Extent of damage (\%); AC5 Percentage of households protected from floods compared to the target (850 households) (\%). In addition, 02 AA indicators are selected for consultation, namely AA1 - Percentage of new planted mangrove forests compared to the target (\%); and AA2 - Percentage of restored mangrove forests compared to the target (30 ha). Three SD indicators are set up as follow: SD1 - Percentage of local population to get benefit directly from the project $(\%)$; SD2 - Enhancing diversity of coastal ecosystems (Yes/No); SD3 - Reducing the process of coastal erosion, wave barrier, and sand barrier (Yes/No).

Round 1: The manual of these indicators was included in the decision approving the project (Quang Ngai's PPC, 2013). Ten indicators were selected. The result of consultation was listed in the Table 2 . The result of $1^{\text {st }}$ round shows that 8 out of 10 indicators have meet the criteria for analysing the ratings from multiple experts with Delphi approach (the rating mean $\left(\mathrm{q}_{\mathrm{i}}\right) \geq 3.5, \mathrm{Q} \leq$ $0.5) ; 2$ out of 10 indicators shows that the rating mean $\left(\mathrm{q}_{\mathrm{i}}\right)<3.5$. The consultation is continued for the Round 2.

Round 2: the indicators were sent to the relevant experts for consultation in the Round 2. The result shows that:

The Quartile deviation (Q) of 10 indicators are equal or less than 0.5; The rating mean of 8 indicators (AC1, AC4, AC5, AA1, AA2, SD1, SD2, SD3) are higher than 3.5; and the rating variance of 8 indicators (AC1, $\mathrm{AC} 4, \mathrm{AC} 5, \mathrm{AA} 1, \mathrm{AA} 2, \mathrm{SD} 1, \mathrm{SD} 2, \mathrm{SD} 3)$ are less than 
$15 \%$. Therefore no further consultation is needed for these 8 indicators;

The Quartile deviation (Q) of 02 indicators (AC2, AC3) are less than 0.5 ; the rating mean are less than 3.5 ; and the rating variance are higher than $15 \%$. Therefore these 2 indicators are rejected.

Almost 8 indicators are ranked from 4-5 (likely relevant or highly relevant). Even those 2 rejected indicators are ranked 3-4 (more or less relevant or likely relevant), these indicators could be re-consulted further. Eight indicators could be used to monitor the progress of 'Reforestation and restoration of coastal mangroves in Binh Thuan Commune, Binh Son district, Quang Ngai province" project.

\section{Conclusions}

The indicators to monitor the progress of one adaptation project in forestry sector have been identified by using the Delphi Technique. The result showed that 8 out of 10 indicators were selected and ranked from 4-5 (likely relevant to highly relevant). Meanwhile the 2 omitted indicators were rated from 34 (more or less relevant to likely relevant). As indicated by the experts, these indicators are not really related to the project outcome, and effectiveness of adaptation action is unclear.

The set of indicators were identified by the Delphi Technique with the comments from qualified expert panel. Hence the set of indicators is reliable to assess the effectiveness of the adaptation actions. Quang Ngai province has invested a number of adaptation actions in forestry sector with resources from state budget as well as from development partners. Applying the set of indicators for other adaptation projects helps to enhance the transparency on support and implementation. Monitoring the adaptation action could contribute to the development of adaptation MRV system, attracting more investment for Quang Ngai province. Furthermore the set of indicators could be extended to other provinces which has the same project type and socio economic conditions. The set of indicators need to be further researched in order to evolve into a general framework to monitor the implementation progress of adaptation action at provincial level.

\section{References}

1. An Thinh Nguyen, Anh Dung Vu, Giang.T.H.Dang, Anh Huy Hoang, Luchens. (2017). How do local community adapt to climate change along heavily damage coasts? A stake holder Delphi study in Ky Anh Central (Viet Nam). Environment Development and Sustainability. 10.1007/s10668-017-9908-x

2. Chu HC, Hwang GJ 2007. A Delphi-Based Approach to Developing Experts System with the Cooperation of Multiple Experts. Experts System with Application, pp.1-15, (article in press)

3. GIZ, WRI. 2011. Making Adaptation Count, concept and option for monitoring and evaluation of climate adaptation

4. Harold A. Linstone. 2002. The Delphi Technique Techniques and Applications

5. Le Trinh Hai Nguyen An Thinh Tran Anh Tuan Dao Dinh Cham Luu The Anh Hoang Luu Thu Thuy Nguyen Manh Ha Tran Quoc Bao Le Van Huong Uong Dinh Khanh Bui Thi Mai Phuc Tuan Tong Quang Hai Truong Hoang Hai. (2015). "Impacts of climate change on agro-ecological landscapes in the coastal area of the Thai Binh province (Vietnam) using the Delphi technique". International Journal of Climate Change Strategies and Management, Vol. 7 Iss 2 pp

6. Le Trinh Hai, Pham Hoang Hai, Nguyen Truong Khoa and Luc Hens. 2009. Indicators for sustainable development in the Quang Tri Province, Viet Nam. J Hum Ecol, 27(3): 217-227

7. People's Committee of Quang Ngai province. 2015. Report on summary of National Target program to respond to climate change for the period of 2010-2015

8. Quang Ngai's PPC. 2013. The Decision No.1470/QD-UBND dated on 10th October 2013 on the approval of project "Reforestation and restoration of coastal mangroves in Binh Thuan Commune, Binh Son district, Quang Ngai province" 
Developing the Indicators for Monitoring the Adaptation Actions for Quang Ngai Province, Viet Nam using the Delphi Technique

Table 2. Analysis of ratings in the Round 1 and Round 2

The project "'Reforestation and restoration of coastal mangroves in Binh Thuan commune, Binh Son district, Quang Ngai province"

\begin{tabular}{|c|c|c|c|c|c|c|c|c|c|c|c|c|c|c|c|}
\hline \multirow[t]{2}{*}{ No } & \multirow[t]{2}{*}{ Indicators } & \multirow{2}{*}{$\begin{array}{l}\text { Questionnair } \\
\text { e Round }\end{array}$} & \multicolumn{9}{|c|}{ Rating by experts } & \multirow{2}{*}{$\begin{array}{l}\text { Rating } \\
\text { Media } \\
\text { n (Md) }\end{array}$} & \multirow{2}{*}{$\begin{array}{c}\text { Quartile } \\
\text { deviatio } \\
n(Q)\end{array}$} & \multirow{2}{*}{$\begin{array}{c}\text { Ratin } \\
g \\
\text { Mean }\end{array}$} & \multirow{2}{*}{$\begin{array}{c}\text { Rating } \\
\text { Varianc } \\
\boldsymbol{e}(\%)\end{array}$} \\
\hline & & & 1 & 2 & 3 & 4 & 5 & 6 & 7 & 8 & 9 & & & & \\
\hline $\begin{array}{c}A C \\
\text { Indicato } \\
s\end{array}$ & & & & & & & & & & & & & & & \\
\hline \multirow[b]{2}{*}{$A C l$} & \multirow{2}{*}{$\begin{array}{l}\text { - Percentage of } \\
\text { mangrove forests } \\
\text { of the total } \\
\text { natural land area: } \\
\text { Not any (0): } 0 \% \\
\text { Little (1): } 0-5 \% \\
\text { Medium (2): } 5- \\
10 \% \\
\text { High (3): } 10-15 \% \\
\text { Very high (4): } \\
15-20 \%\end{array}$} & Round 1 & 5 & 5 & 5 & 4 & 5 & 5 & 5 & 4 & 5 & 5 & 0.25 & 4.8 & 0 \\
\hline & & Round 2 & 5 & 5 & 5 & 4 & 5 & 5 & 5 & 4 & 5 & 5 & 0.25 & 4.8 & \\
\hline \multirow[b]{2}{*}{$\mathrm{AC} 2$} & \multirow{2}{*}{$\begin{array}{l}\text { - Salinity: } \\
\text { Not affected by } \\
\text { saltwater } \\
\text { intrusion: } 0.02 \text { to } \\
0.5 \mathrm{~g} / 1(0) \\
\text { Not affect crops: } \\
0.5 \text { to } 0.75 \mathrm{~g} / 1 \\
\text { (1) } \\
\text { Not affect } \\
\text { strongly crops: } \\
0.75 \text { to } 2.5 \mathrm{~g} / 1 \\
(2) \\
\text { Affect strongly } \\
\text { crops: } 2.5 \text { to } 4 \mathrm{~g} / \\
1 \text { (3) } \\
\text { Affect seriously } \\
\text { crops:> } 4 \mathrm{~g} / 1 \text { (4) }\end{array}$} & Round 1 & 4 & 3 & 3 & 4 & 4 & 3 & 4 & 3 & 3 & 3 & 0.5 & 3.4 & 22.2 \\
\hline & & Round 2 & 3 & 3 & 3 & 4 & 4 & 3 & 3 & 3 & 3 & 3 & 0.25 & 3.2 & \\
\hline \multirow[b]{2}{*}{ AC3 } & \multirow{2}{*}{$\begin{array}{l}\text { - Percentage of } \\
\text { saltwater } \\
\text { intrusion areas: } \\
75-100 \%(0) \\
51-75 \%(1) \\
25-50 \%(2) \\
1-25 \% \text { (3) } \\
0 \%(4)\end{array}$} & Round 1 & 3 & 3 & 4 & 4 & 3 & 4 & 3 & 3 & 4 & 3 & 0.5 & 3.4 & 22.2 \\
\hline & & Round 2 & 3 & 3 & 4 & 4 & 3 & 3 & 3 & 3 & 3 & 3 & 0.25 & 3.2 & \\
\hline \multirow[b]{2}{*}{ AC4 } & \multirow{2}{*}{$\begin{array}{l}\text { - Damage Level } \\
\text { Complete } \\
\text { damage:> 70\% } \\
\text { (0) } \\
\text { Very heavy } \\
\text { damage: } 50-70 \% \\
\text { (1) }\end{array}$} & Round 1 & 4 & 5 & 4 & 5 & 4 & 4 & 5 & 5 & 5 & 4 & 0.5 & 4.6 & 11.11 \\
\hline & & Round 2 & 4 & 5 & 4 & 5 & 4 & 5 & 5 & 5 & 5 & 5 & 0.5 & 4.7 & \\
\hline
\end{tabular}




\begin{tabular}{|c|c|c|c|c|c|c|c|c|c|c|c|c|c|c|c|}
\hline & $\begin{array}{l}\text { Heavy damage: } \\
30 \text { - } 50 \%(2) \\
\text { Partial damage: } \\
<30 \% \text { (3) } \\
\text { No Damage: } 0 \% \\
\text { (4) }\end{array}$ & & & & & & & & & & & & & & \\
\hline \multirow[b]{2}{*}{ AC5 } & \multirow{2}{*}{$\begin{array}{l}\text { - Percentage of } \\
\text { households } \\
\text { protected from } \\
\text { floods compared } \\
\text { to the target ( } 850 \\
\text { households) } \\
\text { Not any (0): } 0 \% \\
\text { Few (1): 0-25\% } \\
\text { Medium (2): } 26- \\
50 \% \\
\text { High (3): } 51-75 \% \\
\text { Very high (4): } \\
76-100 \%\end{array}$} & Round 1 & 5 & 5 & 4 & 5 & 4 & 4 & 5 & 5 & 5 & 5 & 0.5 & 4.7 & 0 \\
\hline & & Round 2 & 5 & 5 & 4 & 5 & 4 & 4 & 5 & 5 & 5 & 5 & 0.5 & 4.7 & \\
\hline $\begin{array}{c}A A \\
\text { Indicator } \\
s\end{array}$ & & & & & & & & & & & & & & & \\
\hline \multirow[b]{2}{*}{ AA1 } & \multirow{2}{*}{$\begin{array}{l}\text { Percentage of } \\
\text { new planted } \\
\text { mangrove forests } \\
\text { compared to the } \\
\text { target (100 ha) } \\
\text { Not yet } \\
\text { implemented: } 0 \% \\
\text { (0) } \\
\text { Newly } \\
\text { implemented: } 1 \text { - } \\
50 \%(1) \\
\text { Nearly complete: } \\
51-99 \%(2) \\
\text { Complete: } 100 \% \\
\text { (3) }\end{array}$} & Round 1 & 5 & 4 & 5 & 5 & 5 & 5 & 5 & 4 & 5 & 5 & 0.25 & 4.8 & 11.11 \\
\hline & & Round 2 & 5 & 5 & 5 & 5 & 5 & 5 & 5 & 4 & 5 & 5 & 0 & 4.9 & \\
\hline \multirow[b]{2}{*}{ AA2 } & \multirow{2}{*}{$\begin{array}{l}\text { - Percentage of } \\
\text { restored } \\
\text { mangrove forests } \\
\text { compared to the } \\
\text { target (30 ha) } \\
\text { Not yet } \\
\text { implemented: } 0 \% \\
\text { (0) } \\
\text { Ongoing: } 1-50 \% \\
\text { (1) } \\
\text { Nearly complete: } \\
51-99 \%(2) \\
\text { Complete: } 100 \% \\
(3)\end{array}$} & Round 1 & 4 & 5 & 4 & 5 & 4 & 5 & 5 & 5 & 4 & 5 & 0.5 & 4.6 & \\
\hline & & Round 2 & 4 & 5 & 4 & 5 & 4 & 5 & 5 & 5 & 5 & 5 & 0.5 & 4.7 & \\
\hline \multicolumn{16}{|c|}{$\begin{array}{c}S D \\
\text { Indicator }\end{array}$} \\
\hline SD1 & '- Percentage of & Round 1 & 4 & 5 & 3 & 5 & 4 & 4 & 4 & 5 & 5 & 4 & 0.5 & 4.3 & 11.11 \\
\hline
\end{tabular}




\begin{tabular}{|c|c|c|c|c|c|c|c|c|c|c|c|c|c|c|c|}
\hline & $\begin{array}{l}\text { local population } \\
\text { to get benefit } \\
\text { directly from the } \\
\text { adaptation action: } \\
\text { No one: } 0 \%(0) \\
\text { Small part of the } \\
\text { population: } 1 \text { - } \\
\text { 30\%: (1) } \\
\text { Large part of the } \\
\text { population: } 31- \\
70 \%(2) \\
\text { The entire } \\
\text { population: } 71- \\
100 \%(3)\end{array}$ & Round 2 & 4 & 5 & 3 & 5 & 4 & 5 & 4 & 5 & 5 & 5 & 0.5 & 4.4 & \\
\hline \multirow[b]{2}{*}{ SD2 } & \multirow{2}{*}{$\begin{array}{l}\text { - Enhancing } \\
\text { diversity of } \\
\text { coastal } \\
\text { ecosystems } \\
\text { Yes: } 1 \\
\text { No: } 0\end{array}$} & Round 1 & 5 & 5 & 5 & 4 & 5 & 5 & 5 & 4 & 5 & 5 & 0.25 & 4.8 & 11.11 \\
\hline & & Round 2 & 5 & 5 & 5 & 5 & 5 & 5 & 5 & 4 & 5 & 5 & 0 & 4.9 & \\
\hline \multirow[b]{2}{*}{ SD3 } & \multirow{2}{*}{$\begin{array}{l}\text { - Reducing the } \\
\text { process of coastal } \\
\text { erosion, wave } \\
\text { barrier, sand } \\
\text { barrier } \\
\text { Yes: } 1 \\
\text { No: } 0\end{array}$} & Round 1 & 5 & 5 & 5 & 4 & 5 & 5 & 5 & 5 & 5 & 5 & 0 & 4.9 & 0 \\
\hline & & Round 2 & 5 & 5 & 5 & 4 & 5 & 5 & 5 & 5 & 5 & 5 & 0 & 4.9 & \\
\hline
\end{tabular}

